\title{
Hypertension among human immunodeficiency virus infected patients on treatment at Parirenyatwa Hospital: A descriptive study
}

\begin{tabular}{|c|c|}
\hline \multicolumn{2}{|c|}{$\begin{array}{l}\text { Authors: } \\
\text { Rumbidzai Chireshe }{ }^{1} \\
\text { Keshena Naidoo } \\
\text { Rudo Nyamakura }{ }^{3}\end{array}$} \\
\hline \multicolumn{2}{|c|}{$\begin{array}{l}\text { Affiliations: } \\
{ }^{1} \text { Discipline of Nursing and } \\
\text { Public Health, University of } \\
\text { KwaZulu-Natal, Durban, } \\
\text { South Africa }\end{array}$} \\
\hline \multicolumn{2}{|c|}{$\begin{array}{l}{ }^{2} \text { School of Nursing, Public } \\
\text { Health and Family Medicine, } \\
\text { University of KwaZulu-Natal, } \\
\text { Durban, South Africa }\end{array}$} \\
\hline \multicolumn{2}{|c|}{$\begin{array}{l}\text { 3Department of Nursing } \\
\text { Science, College of Health } \\
\text { Sciences, University of } \\
\text { Zimbabwe, Harare, } \\
\text { Zimbabwe }\end{array}$} \\
\hline \multicolumn{2}{|c|}{$\begin{array}{l}\text { Corresponding author: } \\
\text { Rumbidzai Chireshe, } \\
\text { rchireshe1@yahoo.ca }\end{array}$} \\
\hline \multicolumn{2}{|c|}{$\begin{array}{l}\text { Received: } 11 \text { Oct. } 2018 \\
\text { Accepted: } 01 \text { Mar. } 2019 \\
\text { Published: } 19 \text { Aug. } 2019\end{array}$} \\
\hline \multicolumn{2}{|c|}{$\begin{array}{l}\text { How to cite this article: } \\
\text { Chireshe R, Naidoo K. } \\
\text { Hypertension among human } \\
\text { immunodeficiency virus } \\
\text { infected patients on } \\
\text { treatment at Parirenyatwa } \\
\text { Hospital: A descriptive study. } \\
\text { Afr J Prm Health Care Fam } \\
\text { Med. 2019;11(1), a1974. } \\
\text { https://doi.org/10.4102/ } \\
\text { phcfm.v11i1.1974 }\end{array}$} \\
\hline \multicolumn{2}{|c|}{$\begin{array}{l}\text { Copyright: } \\
\text { (C) 2019. The Authors. } \\
\text { Licensee: AOSIS. This work } \\
\text { is licensed under the } \\
\text { Creative Commons } \\
\text { Attribution License. }\end{array}$} \\
\hline \multirow{2}{*}{ 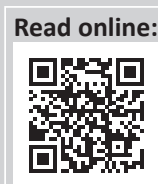 } & \\
\hline & $\begin{array}{l}\text { Scan this QR } \\
\text { code with your } \\
\text { smart phone or } \\
\text { mobile device } \\
\text { to read online. }\end{array}$ \\
\hline
\end{tabular}

Background: Since the roll-out of antiretroviral therapy (ART) in sub-Saharan Africa (sSA) in the early 2000s, the life expectancy of people infected with the human immunodeficiency virus (HIV) has increased. However, the gains made in reducing mortality from HIV-related complications have been mitigated by the emergence of age-related chronic non-communicable diseases (NCDs), such as hypertension. Protease inhibitors (PIs), and prolonged exposure to highly active ART (HAART) have been implicated in the development of hypertension in HIV-positive people.

Aim: To investigate the prevalence of hypertension and its associated risk factors among HIV-positive patients receiving ART.

Setting: The study was carried out at an urban-based clinic that provides HAART and primary care to HIV-positive people in Harare, Zimbabwe.

Methods: A descriptive, cross-sectional study was conducted among non-pregnant adults on HAART attending the clinic between July and August 2018.

Results: We studied $600 \mathrm{HIV}$-positive adult patients, of which $56 \%$ were women. The prevalence rate of hypertension was $29.9 \%$. Of the participants in the hypertensive group, $11.2 \%$ were not previously diagnosed or on treatment. Factors associated with hypertension were advanced age, use of HAART for longer than 10 years, being overweight, a family history of hypertension and smoking. There was a $68.8 \%$ prevalence of body mass index greater than $25 \mathrm{~kg} / \mathrm{m}^{2}$ among all participants.

Conclusion: High hypertension prevalence was recorded. Hypertension was not associated with gender or use of PI regimens but being overweight was highly prevalent. Greater vigilance and integration of resources is required in the overall treatment and monitoring of HIV-positive patients for co-morbidities.

Keywords: hypertension prevalence; HIV-positive; highly active antiretroviral therapy; sub-Saharan Africa; protease inhibitors; antiretroviral therapy; non-communicable diseases.

\section{Introduction}

According to statistics from the United Nations, there were over 36.9 million people worldwide in 2017 who were known to be human immunodeficiency virus (HIV)-positive. ${ }^{1}$ Sub-Saharan Africa (sSA) is the most affected, with an estimated two-thirds of all HIV-positive people living in this region. ${ }^{2}$ The availability and use of highly active antiretroviral therapy (HAART) in sSA is expanding rapidly, with 21.7 million patients estimated to be on treatment by the end of $2017 .{ }^{1}$ Since the roll-out of ART almost two decades ago, the mortality rate from HIV-related complications and AIDS has decreased, resulting in improved survival of people living with HIV., ${ }^{3,5}$ However, the quality of these extended years is unclear. ${ }^{6}$ Zanetti et al. suggested that HIV-positive patients on HAART may be at increased risk for cardiovascular morbidity. ${ }^{7}$ This could be because of chronic inflammation caused by the HIV, the metabolic effects of HAART or the result of other risk factors in HIV-positive people. ${ }^{3}$ Increased life expectancy is also accompanied by diseases associated with ageing such as hypertension. Hypertension and other chronic non-communicable diseases (NCDs) are an increasing public health concern in sSA. ${ }^{8}$ In a research performed in 2017, it was observed that the prevalence rate of participants who reported themselves as hypertensive ranged from $14.1 \%$ in Ghana to $40.8 \%$ in Russia, whereas the prevalence rate of measured hypertension ranged from $38.8 \%$ in India to $73.8 \%$ in South Africa; this may be because of increased life expectancy in sSA, lack of physical activities, smoking, poor diet and obesity. ${ }^{8}$ As yet, there is 
little data on the prevalence of chronic NCD co-morbidities in the HIV-positive population.

A meta-analysis study published in 2015 showed that the burden of hypertension in SSA has been growing over the years. The average prevalence of hypertension in SSA was estimated at $22.9 \% .{ }^{9}$ The prevalence rate of hypertension in Zimbabwe was estimated to be $25 \%$ in the general population in 2015. ${ }^{10}$ Factors associated with hypertension were age, smoking and obesity. ${ }^{10}$

Few studies have investigated the prevalence of hypertension or associated factors in HIV-infected people on HAART in sSA. A meta-analysis published in 2017 estimated that $25.2 \%$ of HIV-positive people worldwide are hypertensive. However, only ten of the studies were from Africa, and none from Zimbabwe. ${ }^{11}$ Risk factors for hypertension were antiretroviral therapy and older age. Prior to the availability of HAART, hypertension in HIV-positive people was seen as secondary to HIV-related complications such as HIVassociated nephropathy (HIVAN) and vasculopathy. $12,13,14$ Other conventional risk factors for hypertension such as obesity and advanced age are becoming increasingly prevalent in HIV-positive populations. ${ }^{10,11,15}$

A study in Ethiopia investigated the prevalence and risk of metabolic syndrome in HIV-positive people on HAART in 2010. This study found out that those who were taking HAART for a longer duration had higher chances of developing metabolic complications. ${ }^{16}$ Another study that was carried out in Kenya noted that there is a high prevalence of obesity and hypertension among HIV-positive people. This high prevalence varied between women and men. ${ }^{17}$

The main purpose of the research study was to investigate the hypertension prevalence rate and its associated risk factors among HIV-positive patients attending the ART clinic at the Parirenyatwa Central Hospital, Zimbabwe.

\section{Methods}

We conducted a descriptive, cross-sectional study among HIV-positive adult patients attending the opportunistic infections (OI)-ART Clinic at Parirenyatwa Central Hospital between July and October 2018. This health clinic provides HAART to over 13000 people living with HIV (PLWH) in Harare, Zimbabwe. ${ }^{8}$

\section{Sampling strategy}

Non-pregnant, HIV-positive patients who were 18 years and above were recruited to participate in the study. Pregnant patients were excluded as hypertension in pregnancy is often a self-limiting condition with a different aetiology to primary hypertension. The ART clinic provides care to approximately 1000 HIV-positive patients per month. Approximately $30 \%$ of monthly clinic attendees were sampled during the study period. A sample size of 600 , in a proportion of 17:20:13 for those on antiretroviral therapy for $\leq 5$ years, between 5 and
10 years and $\geq 10$ years, was determined after consultation with the biostatistician to be adequately powered to determine the casual relationship between the length of exposure to HAART and the risk for hypertension.

The total sample size was calculated as shown below.

\section{Sample size calculation}

- Estimate of the expected proportion $(p)$ of patients who have developed hypertension $=0.5$.

- Desired level of absolute precision $(d)=0.5$.

- Estimated design effect $(\mathrm{DEFF})=1.5$.

$$
\begin{aligned}
& n=\frac{1.96^{2} p(1-p)(D E F F)}{d^{2}} \\
& n=\frac{1.96^{2} \times .5 \times .5(1.5)}{.05^{2}}=576.24 .
\end{aligned}
$$

- Assuming $4 \%$ will decline to participate in the study.

Minimum sample size $=576.24+23.44=599.68$.

\section{Data collection}

A structured interviewer-administered questionnaire and physical examination was used to collect data from the patients. The questionnaire was adapted from the World Health Organization STEPS ${ }^{1}$ instrument. Socio-demographic and medical data were collected from participants, that is, age, gender, weight, height, blood pressure record, history of hypertension in the family and duration of HAART. Patient medical records were used to obtain and confirm reported diagnoses, previous blood pressure readings and hypertension medication. Questionnaires were translated into a vernacular language (Shona) and data were collected by the interviewer.

Education was categorised according to the levels of education, namely, primary school, secondary school, tertiary education and no basic education. We collected employment data in pre-coded categories: employed, self-employed, student, unemployed, housewife or husband and retired. We further collected data on salaries using salary brackets of US $\$ 100.00-\$ 300.00, \$ 301.00-\$ 500.00$, above $\$ 500.00$ and no salary at all.

We also collected data on physical activities with three categories, namely, yes, no and daily chores. 'Yes' was for those who were actively doing exercises, while 'no' was for those who did not do physical activities, and finally, 'daily household chores' was a category for those who were not actively doing exercise but were doing household chores such as gardening, house cleaning and fetching of water and firewood. Data about behavioural risk factors such as smoking and alcohol consumption were also collected.

1.The word STEP in the approach denotes the three steps taken in the surveillance approach. Step 1: Is surveillance of social demographic/key behavoural variables; Step 2: Is physical measurements and Step 3: Is biochemical measurements. 
Data collected for smoking were categorised as 'yes' for smokers and 'no' for non-smokers. Alcohol consumption had three categories, namely, 'yes', 'no' and 'occasional drinking'. 'Yes' was for those who drink alcohol every day or week, while 'no' was for those who did not drink alcohol and the final category was for occasional drinkers.

The body mass index (BMI) of participants was calculated by dividing the weight in kilograms by height in square metres. Weight was assessed using a digital clinical scale and height was measured using a wall-mounted tape measure. Body mass index was classified as follows: below $18.5 \mathrm{~kg} / \mathrm{m}^{2}$ as underweight, $18.5 \mathrm{~kg} / \mathrm{m}^{2}-24.9 \mathrm{~kg} / \mathrm{m}^{2}$ as normal weight, $25.0 \mathrm{~kg} / \mathrm{m}^{2}-29.9 \mathrm{~kg} / \mathrm{m}^{2}$ as overweight and above $30 \mathrm{~kg} / \mathrm{m}^{2}$ as obese.

Blood pressure was measured three times in all participants using a calibrated automated sphygmomanometer machine after the participant had rested for 10 minutes in a quiet room. The average of the last two blood pressure readings was then used for analyses:

Patients were classified as hypertensive if they fulfilled one of the following criteria:

- documentation of hypertension in patient record

- two or more blood pressure readings of $>140 / 90$ at two different visits

- self-reporting of prior diagnosis of hypertension.

\section{Data analysis}

Analyses of raw data were performed with the IBM SPSS Statistics version 25. Descriptive statistics and medians were analysed statistically. Estimated odds ratios (ORs) and 95\% confidence intervals that were used to check the associations between hypertension and other potential risk factors were calculated using logistic regression. The associations between hypertension and risk factor variables were calculated using the $p$-values. A $p$-value of less than 0.10 was determined to be significant.

A bivariate logistic regression model was also used to examine the relationship between hypertension and age, gender, family history of hypertension, education level, employment status, salary, alcohol consumption as well as clinical variables of BMI and duration of HAART.

\section{Study validity}

All HIV-positive patients attending the Parirenyatwa Hospital Opportunistic Infection (OI) Clinic during the study period were given an equal opportunity to participate in this study. Study bias was avoided by use of a protocol for the collection, measurement and interpretation of information. A standardised questionnaire adapted from a validated tool was used. All data were collected by the primary investigator following the principles of good clinical practice. Medical data provided by participants were verified by medical records to avoid information bias.

\section{Ethical considerations}

Ethical approval was obtained from the University of KwaZulu-Natal Biomedical Ethics Committee (BE085/18) and from the University of Zimbabwe, Joint Research Ethics Committee (JREC133/18).

Written informed consent was obtained from all study participants. Privacy was accorded during interviews to guarantee confidentiality, and no personal identifiers were included on the questionnaire. All due care was taken to avoid discomfort to the participants.

Linkage of care was provided to participants who were diagnosed with hypertension for the first time during this study, and participants known to be hypertensive but not on treatment. They were referred, with consent, to a clinician for further investigation and management.

\section{Results}

\section{Profile of participants}

We enrolled $600 \mathrm{HIV}$-positive participants into the study, of which $56 \%(n=334)$ were women. As described in Table 1, the mean age was 41.8 years (range $18-74$ years). The majority of participants were 40 years and older (57\%). There was a high literacy rate with over $80 \%$ of participants having completed secondary schooling. Most participants were employed $(57.5 \%)$. The prevalence of being overweight or obese (i.e. a BMI greater than $25 \mathrm{~kg} / \mathrm{m}^{2}$ ) was $68.8 \%$. Participants who were on first-line treatment were $70 \%$ ( $n=421), 29 \%(n=173)$ were on second-line treatment and $1 \%$ $(n=6)$ were on third-line treatment. There was a high level of literacy with over half of the participants having completed secondary school and a further $28 \%$ tertiary education. The proportion of participants who were employed was $42 \%$ and over half of the participants had an income of more than $\$ 300.00$ a month (Table 2).

\section{Prevalence of hypertension}

The overall prevalence of hypertension in the study population was $29.7 \%$. There was a higher prevalence of hypertension in men $(31.6 \%)$ than women $(28.1 \%)$, but this was not statistically significant (Table 2). Advanced age was significantly associated with a risk of hypertension. The prevalence of hypertension in participants aged 40 years and older was $29.9 \%$, compared to $29.3 \%$ in participants younger than 40 years $(p<0.01)$.

\section{Social factors}

Social factors such as area of residence and level of personal income showed no association with hypertension (Table 2). A positive or unknown family history of hypertension was positively correlated with the risk of hypertension (OR 2.00; 95\% confidence interval [CI]: 1.00-4.1, $p=0.05$ and OR 3.00; 95\% CI: $1.6-5.5, p=0.00$, respectively) 


\begin{tabular}{|c|c|c|c|c|c|}
\hline Variable & $N$ & Mean & Standard deviation & Minimum & Maximum \\
\hline Age (years) & 600 & 41.8 & 12.7 & 18 & 74 \\
\hline \multicolumn{6}{|l|}{ Age categories } \\
\hline $18-39$ & 259 & 29.8 & 6.6 & 18 & 39 \\
\hline $40-59$ & 280 & 47.9 & 4.7 & 40 & 58 \\
\hline$\geq 60$ & 61 & 64.4 & 3.9 & 60 & 74 \\
\hline BMI & 600 & 29.3 & 7.4 & - & - \\
\hline $\begin{array}{l}\text { Underweight } \\
\left(<18.5 \mathrm{~kg} / \mathrm{m}^{2}\right)\end{array}$ & 29 & 16.6 & 1.3 & 13.5 & 18.4 \\
\hline $\begin{array}{l}\text { Normal } \\
\left(18.5 \mathrm{~kg} / \mathrm{m}^{2}-24.9 \mathrm{~kg} / \mathrm{m}^{2}\right)\end{array}$ & 159 & 22.3 & 1.7 & 18.6 & 25.0 \\
\hline $\begin{array}{l}\text { Overweight } \\
\left(25.0 \mathrm{~kg} / \mathrm{m}^{2}-29.9 \mathrm{~kg} / \mathrm{m}^{2}\right)\end{array}$ & 160 & 27.5 & 1.4 & 25 & 30.0 \\
\hline $\begin{array}{l}\text { Obese } \\
\left(>30 \mathrm{~kg} / \mathrm{m}^{2}\right)\end{array}$ & 252 & 36.3 & 5.0 & 30.0 & 54.1 \\
\hline
\end{tabular}

BMI, body mass index; ART, antiretroviral therapy.

\section{Overweight and obesity}

A high prevalence of being overweight and obesity was noted, with $68.8 \%$ of the study participants found to have a BMI greater than $25 \mathrm{~kg} / \mathrm{m}^{2}$. A greater number of participants in the hypertensive group were overweight or obese $(70.8 \%)$ compared to the non-hypertensive group (68\%). The mean BMI of participants in the hypertensive group was $29.6 \mathrm{~kg} / \mathrm{m}^{2}$ compared to $29.2 \mathrm{~kg} / \mathrm{m}^{2}$ in the normotensive group. There was a significant association between being overweight or obese and hypertension (OR: 0.50; 95\% CI: 0.20-1.70) and (OR: 0.90; 95\% CI: 0.30-2.90), respectively.

\section{Behavioural risk factors}

Very few participants were reported to be smokers $(n=14)$. However, smokers were more likely to be hypertensive than non-smokers. A significant association between hypertension and smoking was observed (OR: 1.00; 95\% CI: 0.231-3.792).

Only seven participants admitted to regular consumption of alcohol (beer) and a further 76 to occasional consumption. As reflected in Table 2, alcohol consumption increased the risk for the development of hypertension. The majority of participants (88.2\%) engaged in daily physical activity, mainly occupational, household chores and travel related. Only a small proportion $(11.8 \%)$ of participants did not engage in any regular physical activity. There was no association found between a sedentary lifestyle and hypertension.

\section{Highly active antiretroviral therapy, age and hypertension}

As shown in Table 3, in order to test the association between age and duration on HAART in influencing the likelihood of a patient to be hypertensive, a multivariate logistic regression is undertaken with previously used age and HAART categories as well as BMI and gender as independent variables. Compared to those patients with $\leq 40$ years and being on HAART less than 5 years, the odds of being hypertensive significantly increased in older ages and with longer duration on ART. Participants aged 60 years and older and those who had been on ART between 5 and 10 years had the highest odds ratio (OR: 8.77; 95\% CI: 3.28-23.47). All HAART categories associated with age $\leq 40$ years, gender and BMI categories had statistically insignificant ORs $(p>0.01)$.

\section{Discussion}

The hypertension prevalence rate of $29.7 \%$ reported in this study among HIV-positive people on HAART is similar to that estimated in other HIV-positive populations, and in the general population of sSA. ${ }^{11,18}$ However, the limited data from SSA countries require larger studies, and studies comparing HIV-negative to HIV-positive populations. Previous studies by Pefura Yone et al. ${ }^{19}$ Ekali et al., ${ }^{20}$ Muhammad et al..$^{21}$ and Njelekela et al..$^{22}$ revealed a higher prevalence of hypertension in HIV-positive patients on HAART compared to HIV-negative people. This is contrary to findings of other studies like that of Dimala et al. ${ }^{23}$ who show that a lower prevalence of hypertension was noted in HIV-positive people receiving HAART. The prevalence rate recorded in this study is comparable to the prevalence rate reported by Mutede et al. ${ }^{24}$

An age of older than 40 years, smoking, alcohol consumption, a family history of hypertension and overweight were all associated with a risk of hypertension. These associations have been previously established in sSA populations, but not in the HIV-positive sub-population. ${ }^{25}$

Gender was not a risk factor for hypertension. Advanced age was significantly associated with a risk of hypertension. In both genders, those who were 40 years and older had a statistically greater risk of being hypertensive than those younger than 40 years. However, the prevalence of hypertension in people younger than 40 years was notably high (29.3\%). This suggests that people under 40 years who are on HAART are more likely to develop hypertension than their HIV-negative peers. Further research comparing HIV prevalence in HIV-positive and negative people under 40 years is needed. A high prevalence of hypertension 
TABLE 2: Descriptive characteristics and factors associated with hypertension in adult human immunodeficiency virus-positive patients at Parirenyatwa Hospital, OI Clinic, in 2018.

\begin{tabular}{|c|c|c|c|c|c|c|c|c|c|c|}
\hline \multirow[t]{2}{*}{ Variable } & \multirow[t]{2}{*}{ Frequency } & \multicolumn{2}{|c|}{ Normotensive } & \multicolumn{2}{|c|}{ Hypertensive } & \multirow[t]{2}{*}{ OR } & \multirow[t]{2}{*}{$Z$} & \multirow[t]{2}{*}{$P$-Value } & \multicolumn{2}{|c|}{$95 \%$ confidence interval } \\
\hline & & $N$ & $\%$ & $N$ & $\%$ & & & & From & To \\
\hline Sample size & 600 & 422 & 70.3 & 178 & 29.7 & - & - & - & - & - \\
\hline \multicolumn{11}{|l|}{ Age, years } \\
\hline $18-39$ & 259 & 183 & 70.7 & 76 & 29.3 & Base category & - & - & - & - \\
\hline $40-59$ & 280 & 197 & 70.4 & 83 & 29.7 & 2.0 & 2.57 & 0.01 & 1.2 & 3.4 \\
\hline$\geq 60$ & 61 & 42 & 68.9 & 19 & 31.1 & 4.9 & 3.82 & 0.00 & 2.2 & 10.9 \\
\hline \multicolumn{11}{|l|}{ Gender } \\
\hline Male & 266 & 182 & 68.4 & 84 & 31.6 & 0.9 & -0.71 & 0.48 & 0.6 & 1.3 \\
\hline Female & 334 & 242 & - & 94 & 28.1 & Base category & - & - & - & - \\
\hline \multicolumn{11}{|l|}{ BMI } \\
\hline Below 18.5 & 29 & 21 & 72.4 & 8 & 27.6 & Base category & - & - & - & - \\
\hline $18.5-24.9$ & 159 & 115 & 72.3 & 44 & 27.7 & 0.4 & -1.38 & 0.17 & 0.1 & 1.4 \\
\hline $25.0-29.9$ & 160 & 112 & 70.0 & 48 & 30.0 & 0.5 & -1.08 & 0.28 & 0.2 & 1.7 \\
\hline$>30.0$ & 252 & 174 & 69.0 & 78 & 31.0 & 0.9 & -0.10 & 0.92 & 0.3 & 2.9 \\
\hline \multicolumn{11}{|l|}{ Smoking } \\
\hline No & 586 & 416 & 71.0 & 170 & 29.0 & Base category & - & - & - & - \\
\hline Yes & 14 & 6 & 42.9 & 8 & 57.1 & 1.0 & 0.06 & 0.95 & 0.2 & 3.8 \\
\hline \multicolumn{11}{|l|}{ Alcohol consumption } \\
\hline No & 517 & 364 & 70.4 & 153 & 29.6 & Base category & - & - & - & - \\
\hline Yes & 7 & 5 & 71.4 & 2 & 28.6 & 11.2 & 2.85 & 0.00 & 2.1 & 59.4 \\
\hline Occasional drinker & 76 & 53 & 69.7 & 23 & 60.3 & 0.8 & -0.74 & 0.46 & 0.4 & 1.5 \\
\hline \multicolumn{11}{|l|}{ Physical activity } \\
\hline No & 71 & 56 & 78.9 & 15 & 21.1 & Base category & - & - & - & - \\
\hline Yes & 51 & 39 & 76.5 & 12 & 23.5 & 1.0 & -0.06 & 0.96 & 0.3 & 2.7 \\
\hline Daily chores as activities & 478 & 327 & 68.4 & 151 & 31.6 & 0.9 & -0.21 & 0.83 & 0.5 & 1.8 \\
\hline \multicolumn{11}{|l|}{ Family history of HPT } \\
\hline No & 157 & 107 & 68.2 & 50 & 31.9 & Base category & - & - & - & - \\
\hline Yes & 146 & 105 & 71.9 & 41 & 28.1 & 2.0 & 1.98 & 0.05 & 1.0 & 4.1 \\
\hline Not sure & 297 & 210 & 70.7 & 87 & 29.3 & 3.0 & 3.45 & 0.00 & 1.6 & 5.5 \\
\hline Duration on HAART & $6.5(4-10)$ & 6 & $3-10(49.3 \%)$ & 7 & $5-9(17 \%)$ & 1.1 & 2.09 & 0.04 & 1.0 & 1.1 \\
\hline \multicolumn{11}{|l|}{ Salary } \\
\hline $100-300$ & 45 & 31 & 68.9 & 14 & 31.1 & 2.2 & 1.67 & 0.095 & 0.9 & 5.6 \\
\hline $301-500$ & 204 & 139 & 68.1 & 65 & 31.9 & 1.7 & 0.99 & 0.32 & 0.6 & 5.1 \\
\hline$>500$ & 132 & 102 & 77.3 & 30 & 22.7 & 0.4 & -1.56 & 0.12 & 0.1 & 1.3 \\
\hline No salary & 219 & 150 & 68.5 & 69 & 31.5 & Base category & - & - & - & - \\
\hline \multicolumn{11}{|l|}{ Education } \\
\hline No formal education & 41 & 27 & 65.9 & 14 & 34.2 & Base category & - & - & - & - \\
\hline Primary education & 80 & 55 & 68.8 & 25 & 31.3 & 1.0 & -0.08 & 0.94 & 0.4 & 2.5 \\
\hline Secondary education & 311 & 213 & 68.5 & 98 & 31.5 & 1.8 & 1.37 & 0.17 & 0.8 & 4.1 \\
\hline Tertiary education & 168 & 127 & 75.6 & 41 & 24.4 & 2.5 & 1.87 & 0.06 & 1.0 & 6.5 \\
\hline \multicolumn{11}{|l|}{ Employment } \\
\hline Student & 53 & 39 & 73.6 & 14 & 26.4 & Base category & - & - & - & - \\
\hline Employed & 251 & 174 & 69.3 & 77 & 30.7 & 11.4 & 2.37 & 0.02 & 1.5 & 85.9 \\
\hline Unemployed & 143 & 101 & 70.6 & 42 & 29.4 & 23.3 & 3.03 & 0.00 & 3.0 & 179.2 \\
\hline Retired & 29 & 18 & 62.1 & 11 & 37.9 & 50.4 & 3.52 & 0.00 & 5.7 & 449.5 \\
\hline House wife or husband & 25 & 17 & 68.0 & 8 & 32.0 & 72.5 & 3.91 & 0.00 & 8.5 & 622.8 \\
\hline Self-employed & 99 & 73 & 73.7 & 26 & 26.3 & 26.4 & 3.15 & 0.00 & 3.4 & 202.2 \\
\hline
\end{tabular}

Note: For categorical variables, factors are shown as number (percentage) and medians [interquartile ranges (IQRs)] for continuous variables.

cons, $\mathrm{Z}-3.88 ; 95 \%$ confidence interval $-0.0 ; 0.01$. For categorical variables, factors are shown as number (percentage) and medians (interquartile ranges [IQR]) for continuous variables especially on the duration on HAART.

OR, odd ratio; BMI, body mass index; HAART, highly active antiretroviral therapy; HPT, hypertension.

in young adults would potentially result in premature cardiovascular morbidities and death.

Patients on HAART in this clinic, as elsewhere in SSA, had a high prevalence of being overweight and obesity. ${ }^{26,27}$ A BMI greater than $25 \mathrm{~kg} / \mathrm{m}^{2}$ increased the odds of being hypertensive. ${ }^{28}$ A greater proportion of women than men with hypertension were found to be overweight or obese. Being overweight, but not obese, was associated with an increased risk of hypertension. A larger sample size would perhaps yield a significant positive association of obesity with hypertension.

Social factors such as marital status, income and area of residence showed no association with hypertension. However, the populations sampled in this study were mostly urban based, with high levels of literacy and personal income. These results cannot be extrapolated to more rural communities. 
TABLE 3: Multivariate logistic regression analysis of factors associated with hypertension in human immunodeficiency virus-positive patients.

\begin{tabular}{|c|c|c|c|c|c|c|}
\hline \multirow[t]{2}{*}{ Variable } & \multirow[t]{2}{*}{ Odds ratio } & \multirow[t]{2}{*}{ s.e. } & \multirow[t]{2}{*}{$z$} & \multirow[t]{2}{*}{$P>|z|$} & \multicolumn{2}{|c|}{$95 \%$ confidence interval } \\
\hline & & & & & From & To \\
\hline \multicolumn{7}{|l|}{ Age } \\
\hline$\leq 40$, HAART $\leq 5$ & Base category & - & - & - & - & - \\
\hline$\leq 40$, HAART $>5 \& \leq 10$ & 1.38 & 0.47 & 0.96 & 0.34 & 0.71 & 2.69 \\
\hline$\leq 40$, HAART $>10$ & 0.58 & 0.34 & -0.93 & 0.35 & 0.18 & 1.85 \\
\hline $40-59$, HAART $\leq 5$ & 0.87 & 0.33 & -0.38 & 0.71 & 0.41 & 1.84 \\
\hline 40-59, HAART > 10 & 2.41 & 0.96 & 2.21 & 0.03 & 1.10 & 5.26 \\
\hline$\geq 60, \mathrm{HAART} \leq 5$ & 2.16 & 1.38 & 1.21 & 0.02 & 0.62 & 7.54 \\
\hline$\geq 60$, HAART $>5 \& \leq 10$ & 8.77 & 4.40 & 4.32 & 0.00 & 3.28 & 23.47 \\
\hline$\geq 60$, HAART $>10$ & 5.64 & 3.28 & 2.98 & 0.00 & 1.80 & 17.64 \\
\hline \multicolumn{7}{|l|}{ Gender } \\
\hline Female & Base category & - & - & - & - & - \\
\hline Male & 0.90 & 0.17 & -0.54 & 0.59 & 0.62 & 1.32 \\
\hline Below 18.5 & Base category & - & - & - & - & - \\
\hline $18.5-24.9$ & 0.88 & 0.46 & -0.24 & 0.81 & 0.32 & 2.44 \\
\hline $25.0-29.9$ & 0.89 & 0.46 & -0.23 & 0.82 & 0.32 & 2.45 \\
\hline$>30.0$ & 1.77 & 0.89 & 1.14 & 0.26 & 0.66 & 4.73 \\
\hline Constant & 0.20 & 0.11 & -2.88 & 0.00 & 0.07 & 0.60 \\
\hline
\end{tabular}

BMI, body mass index; HAART, highly active antiretroviral therapy; s.e., standard error.

Despite low reported rates of smoking and alcohol consumption, both of these factors were significantly associated with hypertension. Although a lack of regular physical activity was not an independent risk factor for hypertension in this study, exercise should still be encouraged among all HIV-positive people on HAART for its global health benefits, especially in case of other cardiovascular risk factors such as high BMI and hypertension.

Higher mean values of age and duration of HIV infection were observed. This could probably be attributed to the increased life expectancy of HIV-positive people since the introduction of HAART. The risk of developing hypertension increased with age and the duration on HAART. Participants who were aged 60 years and above and had been on HAART for 5 years and above had a significantly increased risk of hypertension.

Screening for hypertension needs to be improved as demonstrated in this study. Despite regular clinic attendance, there were still participants enrolled at the clinic who were found to have undiagnosed hypertension. In the hypertensive group, $11.2 \%(n=20)$ of participants were not previously diagnosed. Adherence levels to anti-hypertensive medication were only $62 \%$. This highlights the need to strengthen health systems in order to improve screening, diagnosis and monitoring for chronic NCDs. Integration of services can also help address co-morbidities in people with chronic diseases.

In this study of HIV-positive people on HAART, the prevalence of hypertension was high. Possible factors for the high prevalence rate of hypertension in HIV-positive populations in sSA include differences in HIV disease progression, diet, HAART regimens and health infrastructure. ${ }^{29}$

\section{Limitations}

Our primary analyses were based on a descriptive, crosssectional study; hence, transience between causes and development of hypertension could not be established. Data were collected over a 3-month period and may not necessarily reflect the annual patient profile. The study did not include an HIV-negative control group for comparison. Data regarding adherence and socio-economic background required participants' disclosure of this information. The reliability of this data would depend on participants' truthfulness. Validity of data from participants is limited by the fact that it rarely can be independently verified, and this leaves room for information bias. The study was conducted in an urbanbased clinic in Zimbabwe, and the findings may not be extrapolated to rural populations.

Prolonged exposure to HAART is associated with older age which is a confounding factor in the evaluation of the duration of HAART as an independent risk factor.

\section{Conclusion}

Hypertension is as common among HIV-positive people as in HIV-negative people. Risk factors for hypertension in this HIV-positive population were: age over 40 years, obesity and being overweight, smoking and alcohol consumption and a family history of hypertension. Research findings show no difference between protease-inhibitor-based and other regimens with a risk of hypertension. This suggests that exposure to protease inhibitors is not a risk factor for hypertension in this HIV-positive population. Young adults were found to be developing hypertension despite having few co-morbidities. Further studies are needed to understand which risk factors in HIV-positive people predispose them to hypertension and at an earlier age. 
The need for an integrated approach to primary care is advocated. An integrated chronic care model will improve detection and treatment of co-morbidities in the HIV population in sSA. Greater vigilance is also required by health care providers to screen and treat HIV-positive patients for hypertension, particularly in participants older than 40 years, and participants who have been on HAART for more than 10 years. The number of older adults on HAART will increase because of the increased life expectancy of HIV-positive individuals. Health providers working with this population need to be cognizant of this. ${ }^{30}$ The researchers recommend the use of the Innovative Care for Chronic Conditions Framework to provide guidance in restructuring vertical programmes such as the HIV / ART programme to be a more patient-centred model. ${ }^{30,31,32}$

\section{Acknowledgements}

The authors thank all the subjects involved in this study. Special thanks to the Parirenyatwa Group of Hospitals and the Opportunistic Infections (OI) Clinic for granting the approval for this study. Also, appreciation goes to the staff of the Clinic for their support.

\section{Competing interests}

The authors declare that they have no financial or personal relationships that may have inappropriately influenced them in writing this article.

\section{Authors' contributions}

R.C. was responsible for conceptualising the study, data collection, analysis of results and write-up. K.N. refined the study protocol and the writing of the manuscript. R.N. contributed to the final manuscript.

\section{Funding information}

Funding for this study was obtained from the national research foundation (NRF).

\section{Data availability statement}

The authors confirm that the data supporting the findings of this study are available within the article [and/or] its supplementary materials.

\section{Disclaimer}

'The views and opinions expressed in this article are those of the authors and do not necessarily reflect the official policy or position of any affiliated agency of the authors.'

\section{References}

1. UNAIDS W. Fact sheet: World AIDS Day 2017 [homepage on the Internet]. Geneva: Global HIV Statistics; 2017. [cited 2018 Dec] Available from: http://www.unaids. $\mathrm{org} / \mathrm{sites} /$ default/files/media_asset/UNAIDS_FactSheet_en.pdf.

2. THE GLOBAL HIV/AIDS Epidemic [homepage on the Internet]. 2019 [cited 2019 Jan]. Available from: https://www.kff.org/global-health-policy/fact-sheet/theglobal-hivaids-epidemic.
3. Collaboration ATC. Life expectancy of individuals on combination antiretroviral therapy in high-income countries: A collaborative analysis of 14 cohort studies.
Lancet. 2008;372(9635):293-299. https://doi.org/10.1016/S0140-6736(08)61113-7

4. Mohammadi-Moein HR, Maracy MR, Tayeri K. Life expectancy after HIV diagnosis based on data from the counseling center for behavioral diseases. J Res Med Sci. 2013;18(12):1040

5. Deeks SG, Phillips AN. HIV infection, antiretroviral treatment, ageing, and nonAIDS related morbidity. BMJ. 2009;338:a3172. https://doi.org/10.1136/bmj. a3172

6. Zanetti HR, Roever L, Gonçalves A, et al. Cardiovascular complications of HIV. Int J Cardiovasc Sci. 2018;31(5):538-543.

7. Arokiasamy $\mathrm{P}$, Kowal $\mathrm{P}$, Capistrant BD, et al. Chronic noncommunicable diseases in 6 low-and middle-income countries: Findings from wave 1 of the World Health Organization's study on global Ageing and adult health (SAGE). Am J Epidemiol. 2017;185(6):414-428. https://doi.org/10.1093/aje/kww125

8. Ataklte $F$, Erqou $S$, Kaptoge $S$, et al. Burden of undiagnosed hypertension in sub-Saharan Africa: A systematic review and meta-analysis. Hypertension. 2015;65(2):291-298. https://doi.org/10.1161/HYPERTENSIONAHA.114.04394

9. Mutowo MP, Mangwiro JC, Lorgelly PK, et al. Hypertension in Zimbabwe: A meta-analysis to quantify its burden and policy implications. World J Meta-Anal. 2015;3(1):54-60. https://doi.org/10.13105/wjma.v3.i1.54

10. Xu Y, Chen X, Wang K. Global prevalence of hypertension among people living with HIV: A systematic review and meta-analysis. J Am Soc Hypertens. 2017;11(8):530-540. https://doi.org/10.1016/j.jash.2017.06.004

11. Dau B, Holodniy M. The relationship between HIV infection and cardiovascular disease. Curr Cardiol Rev. 2008;4(3):203. https://doi.org/10.2174/1573403087 85160589

12. Yarasheski KE, Laciny E, Overton ET, et al. 18 FDG PET-CT imaging detects arterial inflammation and early atherosclerosis in HIV-infected adults with cardiovascular disease risk factors. J Inflamm. 2012;9(1):26. https://doi.org/10.1186/1476-9255 9-26

13. Badie S, Rasoulinejad M, Salehi M, et al. Evaluation of echocardiographic abnormalities in HIV positive patients treated with antiretroviral medications. Infect Disord Drug Targets. 2017;17(1):43-51. https://doi.org/10.2174/1871526 516666161205124309

14. Patel P, Rose CE, Collins PY, et al. Noncommunicable diseases among HIVinfected persons in low-income and middle-income countries: A systematic review and meta-analysis. AIDS. 2018;32:S5-S20. https://doi.org/10.1097/QAD. 000000000001888

15. Berhane T, Yami A, Alemseged F, et al. Prevalence of lipodystrophy and metabolic syndrome among HIV positive individuals on highly active anti-retroviral treatment in Jimma, South West Ethiopia. Pan Afr Med J. 2012;13(1):8.

16. Bloomfield GS, Hogan JW, Keter A, et al. Hypertension and obesity as cardiovascular risk factors among HIV seropositive patients in Western Kenya. PLoS One. 2011;6(7):e22288. https://doi.org/10.1371/journal.pone.0022288

17. Gaolathe T, Wirth KE, Holme MP, et al. Botswana's progress toward achieving the 2020 UNAIDS 90-90-90 antiretroviral therapy and virological suppression goals: A population-based survey. Lancet HIV. 2016;3(5):e221-e230. https://doi. org/10.1016/S2352-3018(16)00037-0

18. Hendriks ME, Wit FW, Roos MT, et al. Hypertension in sub-Saharan Africa: Cross-sectional surveys in four rural and urban communities. PLoS One. 2012;7(3):e32638. https://doi.org/10.1371/journal.pone.0032638

19. Amberbir A, Singano V, Matengeni A, et al. Dyslipidemia among rural and urban HIV patients in south-east Malawi. PLoS One. 2018;13(5):e0197728. https://doi. org/10.1371/journal.pone.0197728

20. Todowede OO, Sartorius B. Prevalence of metabolic syndrome, discrete or comorbid diabetes and hypertension in sub-Saharan Africa among people living with HIV versus HIV-negative populations: A systematic review and meta-analysis protocol. BMJ Open. 2017;7(7):e016602. https://doi.org/10.1136/bmjopen-2017-016602

21. Semu H, Zack RM, Liu E, et al. Prevalence and risk factors for overweight and obesity among HIV-infected adults in Dar es Salaam, Tanzania. J Int Assoc Providers AIDS Care (JIAPAC). 2016;15(6):512-521. https://doi.org/10.1177/2325957414542574

22. Yone EWP, Betyoumin AF, Kengne AP, et al. First-line antiretroviral therapy and dyslipidemia in people living with HIV-1 in Cameroon: A cross-sectional study. AIDS Res Ther. 2011;8(1):33. https://doi.org/10.1186/1742-6405-8-33

23. Ekali L, Johnstone L, Echouffo-Tcheugui J, et al. Fasting blood glucose and insulin sensitivity are unaffected by HAART duration in Cameroonians receiving firstline antiretroviral treatment. Diab Metabol. 2013;39(1):71-77. https://doi.org/ line antiretroviral treatment.
$10.1016 / \mathrm{j}$.diabet.2012.08.012

24. Muhammad S, Sani MU, Okeahialam BN. Cardiovascular disease risk factors among HIV-infected Nigerians receiving highly active antiretroviral therapy. Nigerian Med J. 2013;54(3):185. https://doi.org/10.4103/0300-1652.114591

25. Njelekela M, Muhihi A, Aveika A, et al. Prevalence of hypertension and its associated risk factors among 34,111 HAART naïve HIV-infected adults in Dar es Salaam, Tanzania. Int J Hypert. 2016;2016:4. https://doi.org/10.1155/2016/5958382

26. Dimala CA, Atashili J, Mbuagbaw JC, et al. Prevalence of hypertension in HIV/ AIDS patients on highly active antiretroviral therapy (HAART) compared with HAART-naïve patients at the Limbe Regional Hospital, Cameroon. PLoS One. 2016;11(2):e0148100. https://doi.org/10.1371/journal.pone.0148100

27. Mutede BR, Magure T, Gombe NT, et al. Prevalence and factors associated with hypertension among anti-retroviral therapy patients aged 15 years and above in Makonde District, Zimbabwe, 2012: An analytic cross sectional study. World J Cardiovasc Dis. 2015;5(09):266. https://doi.org/10.4236/wjcd.2015.59030

28. Tsikira T. Co-morbidity of diabetes mellitus and HIV in patients attending the ART clinic Parirenyatwa hospital 2015. 2016. 
29. Oni T, McGrath N, BeLue R, et al. Chronic diseases and multi-morbidity-a conceptual modification to the WHO ICCC model for countries in health transition. BMC Publ Health. 2014;14(1):575. https://doi.org/10.1186/1471-2458-14-575

30. Oni T, Youngblood E, Boulle A, et al. Patterns of HIV, TB, and non-communicable disease multi-morbidity in peri-urban South Africa-a cross sectional study. BMC Infect Dis. 2015;15(1):20. https://doi.org/10.1186/s12879-015-0750-1
31. Van der Heide I, Snoeijs S, Melchiorre MG, et al. Innovating care for people with multiple chronic conditions in Europe. Brussels: ICARE4EU; 2015.

32. Rabkin M, Melaku Z, Bruce K, et al. Strengthening health systems for chronic care: Leveraging HIV programs to support diabetes services in Ethiopia and Swaziland. J Trop Med. 2012;2012:6. https://doi.org/10.1155/ 2012/137460 